$S_{\text {eção Livre }}$ 


\title{
EPISTEMOFILIA, USO dos PRAZERES E CUIDADO DE SI: PluRalidade E TolerânCia na Ética Clássica
}

\author{
Francisco Fianco*
}

Resumo: Em diversos aspectos, Michel Foucault poderia ser considerado um dos pensadores mais influentes do século $X X$, principalmente no campo da ética, mais especificamente sobre a sexualidade. Para recuperar estas reflexões, percorreremos, basicamente, as páginas dos três volumes de História da Sexualidade, respectivamente A vontade de saber, $\mathrm{O}$ uso dos prazeres e $\mathrm{O}$ Cuidado de si, a fim de reconstruir seus argumentos principais bem como destacar as importantes questões que esta obra traz no sentido de pensarmos a nossa própria época.

Palavras-chave: Foucault, Sexualidade, Antiguidade Clássica, Uso dos Prazeres, Cuidado de Si.

Abstract: In many ways, Michel Foucault could be considered one of the most influential thinkers of the twentieth century, especially in the field of ethics, more specifically about sexuality. To recover these reflections, we will cover basically the pages of three volumes of History of Sexuality, respectively The Will to Knowledge, The Use of Pleasure and The Care of the Self to rebuild its main arguments and highlight the important issues that they bear on thinking of our own time.

Keywords: Foucault, Sexuality, Classical Antiquity, Use of Pleasure; Care of the Self.

* Doutor em Filosofia e professor do curso de Filosofia da Universidade Federal de Passo Fundo. E-mail: fcofianco@gmail.com 
$|148|$

Epistemofilia, uso dos prazeres e cuidado de si:...

\section{Introdução}

Em diversos aspectos, Michel Foucault poderia ser considerado um dos pensadores mais influentes do século XX. Não apenas pela profundidade penetrante de seu pensamento, ou pela capacidade de buscar em áreas limítrofes à filosofia, como a psicanálise, a sociologia ou a história, como também por suas abordagens inovadoras de aspectos da temática filosófica que já haviam sido elaborados de forma suspeitosamente pacífica pela tradição. Um aspecto específico da filosofia abordado desta maneira inovadora e, por vezes, chocante, é o da ética, mais especificamente da ética clássica e seu processo de transformação até os modelos éticos que conhecemos na modernidade em sua vinculação com a tradição medieval. Filiação disfarçada, mas inegável em uma civilização que cresceu e se desenvolveu inteiramente em um mundo pós-cristianismo. Mais chocante ainda à nossa sensibilidade, nesta abordagem foucaultiana, é o pano de fundo sobre o qual se apresentam suas considerações, o tabu anacrônico e universal da cultura humana, a sexualidade, entendida como palco de articulação preferencial dos modernos mecanismos de dominação social. (Bauman, 1998, p. 180). Para recuperar estas reflexões, percorreremos, basicamente, as páginas dos três volumes de História da Sexualidade, respectivamente $A$ vontade de saber, $O$ uso dos prazeres e $O$ Cuidado de si, a fim de reconstruir seus argumentos principais bem como destacar as importantes questões que estas obras trazem no sentido de pensarmos a nossa própria época.

\section{Epistemofilia}

Um dos primeiros argumentos que podemos destacar no texto do primeiro volume é o de que o sexo é um dos principais aspectos da subjetividade humana a ser relegado à obscuridade da cultura. Muito além de sofrer uma interdição meramente fática, sempre recebeu igualmente uma interdição simbólica através da linguagem, de modo que a censura e a autocensura moral que nos são impostas e da qual nós mesmos participamos necessite criar artifícios para abordar tal assunto. Ou o sexo e o que a ele se 
relaciona é tratado através de termos jocosos ou eufemismos, ou é circunscrito ao jargão técnico, o que faz com que o discurso autorizado seja imbuído de uma aura de seriedade forçada e científica. Nesse aspecto, Foucault diferencia duas posturas epistemológicas em relação ao sexo, a arte erótica e a ciência sexual, ou seja, uma relação com o sexo e o corpo de um ponto de vista global e existencial e sua contrapartida como uma relação de um sujeito autoritário com um objeto inferior e depreciado, desprovido de autenticidade ou dignidade.

\begin{abstract}
Na arte erótica a verdade é extraída do próprio prazer, encarado como prática e recolhido como experiência; [...]. Melhor ainda, este prazer deve recair, proporcionalmente, na própria prática sexual, para trabalhá-la como se fora de dentro e ampliar seus efeitos. [...] Nossa civilização, pelo menos à primeira vista, não possui ars erótica. Em compensação é a única, sem dúvida, a praticar uma scientia sexualis (Foucault, 1988a, p. 57).
\end{abstract}

Foucault desfaz o lugar comum de que a sexualidade sempre foi algo reprimido na cultura chamando a atenção para uma mudança na maneira de abordá-la (Foucault, 1988a, p. 26). Nesse sentido, desmitifica-se a interdição como um dos aspectos principais da abordagem da sexualidade do ponto de vista histórico, de maneira que o próprio fato de sempre nos referirmos a ela enquanto algo interdito disfarça o que verdadeiramente acontece, a sua completa integração ao campo da biogovernamentalidade, ou seja, a sexualidade não sendo o campo do proibido, e sim o campo absoluto do regramento (Foucault, 1988a, p. 28). Em função disso, é falso afirmar que a moralidade moderna é tida como repressora por vetar o sexo, pois tal discurso cumpre com a função de mascarar o fato de que o sexo, muito diferentemente de estar proibido, está na verdade repressivamente normatizado, ou seja, circunscrito aos locais que a cultura lhe reserva, o quarto dos pais, no caso da sexualidade aceita, ou os prostíbulos e consultórios dos especialistas, no caso das sexualidades consideradas desviantes. 
$|150|$

Epistemofilia, uso dos prazeres e cuidado de si:...

Vale fazer aqui a ressalva a respeito da possibilidade de exercício da sexualidade dentro de cada um destes espaços normativos: ao passo que a sexualidade feminina encerrava-se no espaço doméstico, tendo seus desvios encaminhados para a normalização através do discurso médico, de forma análoga à preocupação pedagógica com a masturbação infantil, o exercício da sexualidade masculina por excelência exigia uma maior amplitude, disponibilizada pela sua condição de status superior, como provedor e senhor da casa que cumpre, no contexto familiar, a função que o capataz cumpre na fábrica, o professor na escola, o médico no sanatório, o sargento no exército e o carcereiro na prisão, isso para nos limitarmos a apenas alguns exemplos da personificação da normatividade dos mais diversos aspectos da vida no período moderno (Bauman, 1998, p. 183).

\footnotetext{
Consideremos a hipótese geral do trabalho. A sociedade que se desenvolve no século XVIII - chame-se burguesa, capitalista ou industrial - não reagiu ao sexo com uma recusa em reconhecê-lo. Ao contrário, instaurou todo um aparelho para produzir discursos verdadeiros sobre ele. [...]: através de círculos cada vez mais fechados, o projeto de uma ciência do sujeito começou a gravitar em torno da questão do sexo. Contudo, não devido a alguma propriedade natural inerente ao próprio sexo, mas em função das táticas de poder que são imanentes a tal discurso (Foucault, 1988a, p. 68).
}

Assim, cria-se a normatização da sexualidade através dos discursos médicos e educacionais, especialmente em relação à sexualidade infantil, na qual desempenha especial papel a demonização moral da masturbação. A masturbação, ou sua mera possibilidade, era a evidência da necessidade de controle ubíquo e universal, no modelo de panóptico que Foucault demonstra como o mecanismo moderno de supervisão por excelência, transformando a existência moderna numa espécie de encarceramento (Foucault, 1984, passim).

Tal análise mais detalhada da maneira através da qual a moralidade moderna trata o sexo e a sexualidade demonstra, 
portanto, que esse tabu tão assombroso tornou-se quase um assunto de obrigatoriedade, produzindo não apenas um único, mas toda uma diversidade de discursos normatizadores sobre a sexualidade (Foucault, 1988a, p. 34). Tais discursos se legitimam a partir da possibilidade de serem apropriados por uma ou várias instituições que, através de mecanismos diversos, estabelecem a norma, o padrão, o comportamento socialmente aceitável, criando disposições e protocolos de ação, no que diz respeito à conduta sexual, abrangendo desde a infância até a velhice, cada fase da vida humana com suas condutas "apropriadas". Porém, apesar de todo o esforço de padronização, a multiplicidade da natureza humana se fez sentir nos últimos dois séculos na forma de uma dispersão de formas diferentes de sexualidade, o que ocasionou, por parte do discurso normativo, uma extensa classificação de perversões e desvios, e uma consequente caça a estas idiossincrasias na forma de condenação moral, diagnóstico como doença ou mesmo criminalização.

Essa nova caça às sexualidades periféricas provoca a incorporação das perversões e nova especificação dos indivíduos. [...] O homossexual do século XIX torna-se uma personagem: [...]. Nada daquilo que ele é, no fim das contas, escapa à sua sexualidade. [...] A homossexualidade apareceu como uma das figuras da sexualidade quando foi transferida, da prática da sodomia, para uma espécie de androgenia interior, um hermafroditismo da alma. O sodomita era um reincidente, agora o homossexual é uma espécie (Foucault, 1988a, p. 43).

Tal condenação não significa propriamente uma proibição, e sim uma classificação mais imediata dos comportamentos destoantes. Esse processo termina gerando uma proliferação não das próprias sexualidades destoantes, pois estas já existiam, e sim dos nichos nos quais elas são enquadradas, pois mesmo que as instituições e seus discursos ajam local e especificamente como meios de coibição, uma rede mais vasta e muito mais eficiente se organiza 
|152|

Epistemofilia, uso dos prazeres e cuidado de si:...

para dar possibilidade de vazão a estas pluralidades. Isto fundamenta a afirmação de Foucault de que vivemos em uma "sociedade de perversão explosiva e fragmentada" (Foucault, 1988a, p. 46).

Nesse ímpeto de classificação reside a epistemofilia: o prazer perverso de criar sobre o sexo um saber que é poder, uma capacidade de classificação normatizadora que define o dentro e o fora do socialmente aceito. A moralidade repressora não agiu no sentido de banir, e sim no de construir em torno da sexualidade uma verdade em forma de discurso para determinar o que é o "correto", aspecto que é analisado por Foucault não apenas neste primeiro volume da História da Sexualidade, como também em diversas outras obras, como a História da Loucura, O Nascimento da Clínica, Vigiar e Punir, e, principalmente, em Hermenêutica do Sujeito onde se desenvolvem e abundam exemplos para diversos temas já abordados ao longo dos três volumes sobre a história da sexualidade (Machado, 1981, p. 188 ss.). Essa inter-relação, portanto, entre saber e poder, entre discurso oficial e dominação, perpassa diversas obras foucaultianas.

Nesse ponto, vale retomar os argumentos que traçam a diferenciação conceitual entre sexo e sexualidade dentro do esquema desta obra em especial. Enquanto sexo é entendido como algo fisiológico, visceral, "sexo-natureza (elemento do sistema do ser vivo, objeto para uma abordagem biológica)" sexualidade é entendida como o conjunto de representações simbólicas, referente ao "sexo-história, ao sexo-significação, ao sexo-discurso" (Foucault, 1988a, p. 76) dentro do que o sexo-natureza, por não poder ser exercido em toda a plenitude e crueza de sua matriz biológica, é inserido. "A sexualidade é o correlato desta prática discursiva desenvolvida lentamente, que é a scientia sexualis." (Foucault, 1988a, p. 67) E tal ciência tem como escopo a produção de um conhecimento das subjetividades que gravita fundamentalmente sobre o terreno da sexualidade, ou seja, que pretende, através de seu discurso, constituir um mecanismo de controle das subjetividades que passe por este aspecto (Foucault, 1988a, p. 88). Sexualidade é, portanto, muito diferente deste sexo que é o resquício bestial na humanidade 
e que a cultura se esforçaria por esconder, obscurecer ou enfraquecer. Sexualidade é o mecanismo cultural de produção de simbolizações positivas sobre o sexo, de regulamentação, um dispositivo histórico e produzido como mecanismo de saber e de poder capaz de integrar o sujeito e as diversas relações de micropoder das quais ele participa. Sexualidade, portanto, é muito diferente de algo subterrâneo ou reprimido, e sim justamente a realização daquela intuição que Foucault coloca como hipótese central de seu texto, a de que, como modelo de regulamentação, é mais eficiente compelir a uma exposição constante e cotidiana, controlável, do que obrigar um retraimento da sexualidade a uma obscuridade na qual ela poderia mais confortavelmente florescer. De fato, a questão fundamental de problematicidade da sexualidade humana não parece estar vinculada especificamente à moral, ou seja, a critérios de certo ou errado, e sim a critérios de utilidade ou não dessa sexualidade normatizada pelos mecanismos criados como forma de regulamentação e biopoder (Both, 2009, p. 112 ss.).

E a autoridade do discurso destes mecanismos de interdição se realiza através de sua ligação estreita com o discurso científico, pois é justamente através desse pressuposto, o de uma cientificidade doadora de sentido e fundamentação a tal ponto que pode ser encarada como uma verdadeira mitologia contemporânea, que estas políticas normatizadoras se fundamentam. Surge o papel do especialista, que tem como representantes, por um lado, o médico quanto à normalidade do corpo, e, por outro, o psicanalista enquanto aquele que age no espaço dentro do qual os desvios da sexualidade podem ser "curados" (Foucault, 1988a, pp. 111 e 122).

\section{A relação com os prazeres na moralidade clássica}

No segundo volume de A História da Sexualidade, nosso autor recupera os argumentos desenvolvidos na primeira parte e os utiliza como padrão metodológico para tentar reconstruir o processo de formação de uma hermenêutica do sujeito na antiguidade. Esta abordagem visa não à reconstrução de uma história da moral na 
|154|

Epistemofilia, uso dos prazeres e cuidado de si:...

antiguidade clássica, e sim a uma análise dos jogos de poder e de verdade que constituem a construção desta subjetividade que se pensa eticamente dentro dos limites históricos de seu desenvolvimento.

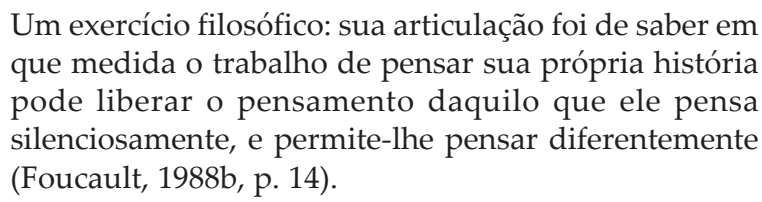

Nesse sentido, este exercício filosófico é o de uma estética de si enquanto uma autoprodução, ou seja, em relação a uma reflexão particular e individual sobre a própria conduta na qual a referência moral seja a própria condição do indivíduo, e não um código de conduta que possa ser exterior. "Deve-se entender, com isso, práticas refletidas e voluntárias através das quais os homens não somente se fixam regras de conduta, como também procuram se transformar, modificar-se em seu ser singular e fazer de sua vida uma obra que seja portadora de certos valores estéticos e responda a certos critérios de estilo" (Foucault, 1988b, p. 15). Assim se contextualiza e exemplifica a perda de importância destas "artes de existência" e "técnicas de si" com o advento da moralidade cristã, que, ao contrário de estimular uma reflexão contínua e específica sobre cada caso cria um código de conduta generalista que deve ser seguido por todos indistintamente, eliminando o espaço de reflexão e consequente autoconstrução moral que existia na maior parte dos sistema morais da antiguidade. É o processo de substituiçãode uma abordagem das problematizações éticas a partir da "prática de si" por uma abordagem histórica da moralidade entendida como conjunto sistemático de proibições. Desse modo, mesmo as problemáticas centrais sobre as quais incide a moralidade em relação ao comportamento sexual têm ênfases distintas nestes dois contextos particulares.

Em suma, sobre todos esses pontos que foram considerados, durante tanto tempo, como tão 


\begin{abstract}
importantes - natureza do ato sexual, fidelidade monogâmica, relações homossexuais, castidade parece que os antigos teriam sido um tanto indiferentes, e que nada disso teria atraído muito sua atenção, nem constituído para eles problemas muito agudos (Foucault, 1988b, p. 17).
\end{abstract}

Isso não equivale a dizer que houve uma ruptura radical na moralidade em função do advento do cristianismo em forma de governo pastoral, de maneira que em uma apreciação em larga escala de tempo se possa tranquilamente perceber tematizações comuns em termos de ética e comportamento tanto entre as sociedades clássicas e o medievo cristão quanto entre estes dois períodos e a nossa reflexão contemporânea. O que muda é, então, a maneira através da qual o assunto estará sendo abordado: enquanto a moralidade cristã tenta desenvolver um padrão universal e impositivo de comportamento, a moralidade clássica tardia, em seus diversos modelos e estágios de desenvolvimento e aceitação, é mais entendida como uma reflexão sugestiva de aceitação individual e não como um padrão de comportamento compulsório; eram moralidades que muitas vezes não concordavam entre si que funcionavam como um distintivo de excelência e diferenciação da população culta e elitizada em relação à maioria da população que se pautava pela moralidade consuetudinária. Nesse sentido, mesmo que aspectos definidos da moralidade cristã já estivessem sendo desenvolvidos por diversos dos sistemas éticos que proliferaram ao longo dos últimos estertores da Filosofia Helenista, isso não significa uma continuidade da moralidade clássica tardia na moralidade cristã. Estamos falando de um período de transição e amalgamento da história do pensamento humano no qual os conceitos de continuidade e de ruptura não podem ser pensados isoladamente.

Nesse momento, destacamos que um dos aspectos fundamentais para a compreensão desta moralidade clássica é o seu elitismo. Não é uma moral que se constitua num código universal. Ela é elitista justamente por ser uma moralidade de uma forma de prática de si que é, nesse sentido, o privilégio 
$|156|$

Epistemofilia, uso dos prazeres e cuidado de si:...

daqueles que têm autoridade para isso: os homens adultos e livres. Ela é uma moralidade viril, pensada por homens e ensinada para homens no intuito de subsidiar a formação moral daqueles destinados a governar a si mesmos e aos demais. É nesse sentido que se pode compreender a conotação negativa da homossexualidade passiva e do caráter efeminado entre homens adultos em oposição à aceitação social deste mesmo comportamento entre os efebos. "A askesis moral faz parte da paidéia do homem livre que tem um papel a desempenhar na cidade e com relação aos outros; [...] tudo isso é, ao mesmo tempo, formação do homem que será útil para a cidade, e exercício moral daquele que quer se dominar a si mesmo" (Foucault, 1988b, p. 71) Tal moralidade é, portanto, o resultado de uma paideia, formação, da virilidade, o desenvolvimento da virtude, aretè, é uma possibilidade exclusivamente masculina, e a problemática do homoerotismo está vinculada ao fato de abrir mão das prerrogativas de atividade moral, governo de si, comando de outros.

\begin{abstract}
Seria inexato ver aí uma condenação do amor pelos rapazes ou daquilo que, em geral, chamaríamos de relações homossexuais; entretanto, é necessário reconhecer aí o efeito de apreciações fortemente negativas a respeito de certos aspectos possíveis da relação entre homens, assim como uma viva repugnância a respeito de tudo o que pudesse marcar uma renúncia voluntária aos prestígios e às marcas do papel viril (Foucault, 1988b, p. 22).
\end{abstract}

A partir de tais considerações, podemos perceber a prática de si enquanto exercício moral na antiguidade como uma relação com a capacidade de autocontrole, como ascese em relação aos prazeres, askésis e aphrodisía, do que especificamente em relação à construção de um código mais amplo e normalizador. "Em todas as coisas, contra o que mais devemos nos precaver é o prazer e o que é agradável, pois não podemos julgá-lo com imparcialidade" (Aristóteles, 2009, Lv. II, 1109b, pp. 5-10). Assim, o que define 
moralmente o valor dos atos e comportamentos não é especificamente o objeto ao qual se lança o desejo do sujeito, e sim a sua capacidade de controle deste desejo no sentido de intensidade, modulação e frequência. É uma questão que pode ser encarada, em um primeiro momento, como quantitativa, oscilando entre a moderação e a incontinência. Ela pode, de certa forma, servir para pensarmos novamente o conceito aristotélico de mediania da virtude sob uma nova ótica, na medida em que tenhamos claro o fato de que, apesar de os sentidos como fonte de prazer, em forma de contemplação estética, serem provas da superioridade humana, os mais nobres destes sentidos, ou destes aphodisia, são a audição e a visão, pois são mais intelectuais, ao passo que o tato e o paladar devolveriam o humano ao bestial do qual tem o dever de se separar (Aristóteles, 2009, Lv. III, 1118a-b). Do ponto de vista qualitativo, porém, a oposição se dá, por sua vez, entre os polos opostos da atividade e da passividade, retomando, de certa forma, o que já havíamos observado sobre a condenação do comportamento homossexual acima.

\begin{abstract}
Mas é preciso sublinhar que, na prática dos prazeres sexuais, distinguem-se claramente dois papéis e dois polos, como também podem ser distinguidos na função generativa; são dois valores de posição - a do sujeito e a do objeto, a do agente e a do paciente: como diz Aristóteles, "a fêmea enquanto fêmea é de fato um elemento passivo, e o macho, enquanto macho, um elemento ativo" (Foucault, 1988b, p. 45).
\end{abstract}

A problematicidade não reside, portanto, naquilo que se pode desejar ou na maneira através da qual se quer executar a satisfação desse desejo. Não reside nem mesmo na dimensão interna do sujeito, como posteriormente se verificaria na moralidade cristã como um aspecto que terminaria por criar a dimensão da culpa pela intenção, exclusivamente interna ao sujeito, o que poderíamos chamar contemporaneamente de espaço psicológico de liberdade ou simplesmente subjetividade. Em outras palavras, não se trata de barrar o desejo em seu próprio surgimento, suprimindo-o para 
$|158|$

Epistemofilia, uso dos prazeres e cuidado de si:...

não "pecar em pensamento", a despeito do paradoxo da expressão. O desejo é natural e incontrolável em sua gênese, a questão ética é a maneira através da qual o sujeito desejante se permite ou não satisfazê-lo.

\begin{abstract}
Questão, não do que é permitido, dentre os desejos que se experimenta ou os atos que se comete, mas questão de prudência, de reflexão, de cálculo na maneira pela qual se distribui e se controla seus atos. No uso dos prazeres, $[. .$.$] , as regras morais às quais os indivíduos$ se submetem são muito distantes daquilo que pode constituir uma sujeição a um código bem definido (Foucault, 1988b, p. 52).
\end{abstract}

A prática de si, nesse aspecto, deve obedecer, ao levar em consideração estes aspectos de prudência e reflexão, a três critérios: o de necessidade, o de oportunidade e o de posição social. O critério de necessidade se relaciona àquilo que a natureza, mediatizada pelo corpo, reclama como seu patrimônio, ou seja, não é um autocontrole no sentido de uma afasia exagerada, como muitas vezes se verifica no comportamento de um estoicismo caricato herdado pelos monges eremitas dos primeiros tempos de cristianismo, e sim de entender e respeitar, no espaço da vivência corporal, as necessidades do corpo, não só em relação à sexualidade como também em relação aos alimentos e às bebidas, ou seja, em relação aos prazeres dos sentidos que já eram fonte de alerta para Aristóteles na Ética à Nicômaco (Aristóteles, 2009, Lv. III, 1118a).

O segundo aspecto, o da oportunidade, kairos, também pode ser entendido como ocasião oportuna, ou seja, a questão não é sobre se tal prática é ou não conveniente em si, e sim em relação ao contexto no qual ela está se desenvolvendo. Isso se liga ao fato de que o sujeito moral, na antiguidade clássica, não é entendido como uma univocidade, ou seja, como alguém que pode ou não pode usufruir determinado prazer em absoluto, e sim que esta possibilidade esteja atrelada ao papel social representado em determinado contexto específico, evidenciando o conceito de ocasião como não exclusivamente temporal, mas também espaço- 
contextual. Daí se origina, então, o terceiro critério, o de posição social, ou status. "Parece que na moral antiga, salvo alguns preceitos que valem para todo mundo, a moral sexual sempre faz parte do modo de vida, ele próprio determinado pelo status que se recebeu e as finalidades que se escolheu" (Foucault, 1988b, p. 57). Esta exigência se liga novamente à necessidade de autocontrole do homem livre destinado a desempenhar papel de autoridade, ou seja, ele deve antes controlar a si mesmo para comprovar a sua capacidade de governar os demais.

\begin{abstract}
Um termo é utilizado na língua clássica para designar essa forma de relação consigo, essa "atitude" que é necessária à moral dos prazeres, e que se manifesta no bom uso que se faz deles: enkrateia. $\mathrm{Na}$ verdade, essa palavra permaneceu durante muito tempo bem próxima de sóphrosuné: elas são, freqüentemente, encontradas juntas ou alternativamente, com acepções bem próximas (Foucault, 1988b, p. 60).
\end{abstract}

Apesar da possível coincidência semântica entre enkrateia e sóphrosuné que uma leitura mais superficial possa nos sugerir, Foucault as diferencia enquanto sendo esta última um comportamento adequado em relação à exterioridade, ou seja, do sujeito moral com os diversos elementos que o cercam, ao passo que a primeira se relacionaria mais ao aspecto de domínio de si, ou seja, diga respeito a um tipo de temperança em relação a si mesmo, uma virtude de domínio de si sobre o uso dos prazeres e dos desejos que revela um antagonismo de si para consigo que é, em última análise, o cerne da prática de si, da arte da existência.

Ser livre em relação aos prazeres é não estar a seu serviço, é não ser seu escravo. $O$ perigo que os aphrodisia trazem consigo é muito mais a servidão do que a mácula (Foucault, 1988b, p. 74).

E a relação entre o uso dos prazeres, aphrodisia, com a prática de si como comportamento moral é justamente a do exercício de 
$|160|$

Epistemofilia, uso dos prazeres e cuidado de si:...

uma capacidade viril de liberdade e temperança, ou seja, o comportamento desejado do senhor é o de controlar a si mesmo no uso do poder que lhe é permitido exercer sobre outrem, o que evidencia que essa moralidade masculina se fixa especificamente na relação de dominação e autocontrole exercida em relação aos outros e a si mesmo do ponto de vista da prática sexual. E tal modelo de moralidade não avalia o destino do desejo e sim a autonomia em relação a este desejo e sua capacidade de controlá-lo ao invés de submeter-se a ele.

\begin{abstract}
A linha de demarcação entre um homem efeminado e um homem viril não coincide com a nossa oposição entre hétero e homossexualidade; ela também não se reduz à oposição entre homossexualidade ativa e passiva. Ela marca a diferença de atitude em relação aos prazeres; [...]. O que constitui, para os gregos, a negatividade ética por excelência, não é, evidentemente, amar os dois sexos; também não é preferir o seu próprio sexo ao outro; é ser passivo em relação aos prazeres (Foucault, 1988b, p. 79).
\end{abstract}

Assim, podemos entender que a substância ética da reflexão grega não estava centrada em critérios de conformidade ou inconformidade em relação a um código ou doutrina, e sim em relação à toda a complexa problematicidade da relação do sujeito moral com os aphrodisia entendidos não apenas como satisfação de necessidades fisiológicas e sim também associados pela natureza humana a um imenso prazer, ao qual ela é compelida de forma violenta e avassaladora e que, justamente por isso, precisa ser controlada. Nesse sentido, ela é muito mais um exercício ético de liberdade do que uma opressão sob uma moralidade constituída (Giacóia, 1995, p. 89). Em função disso, a esquematização moral da antiguidade pode ser entendida como uma estética da existência e não como a moralidade que a sucede, como uma codificação dos atos (Rajchmann, 1987, pp. 36-37).

Pode-se lembrar o que K. J. Dover escrevera: “Os gregos não herdaram a crença de que uma potência 


\begin{abstract}
divina revelara a humanidade um código de leis que regulavam o comportamento sexual, nem entretiveram, eles próprios, essa crença. Também não possuíam uma instituição com o poder de fazer respeitar interdições sexuais. Confrontados com culturas mais antigas, mais ricas e mais elaboradas do que a deles, os gregos sentiram-se livres de escolher, adaptar, desenvolver e, sobretudo, inovar" (Foucault, 1988b, p. 220).
\end{abstract}

Desse modo, diferencia-se da moralidade subsequente não exatamente pela temática, pois ambas debruçaram-se sobre temas semelhantes, como a fidelidade, a hétero ou homossexualidade, a castidade etc., e sim em função de uma tendência à universalização das normas e homogeneização dos comportamentos que contrasta com a estética de si enquanto exercício agonístico consigo mesmo e que naquele contexto fundamentava a exclusividade de mobilidade e liberdade de uma classe específica de pessoas, os homens adultos e livres, os únicos a terem a possibilidade de uma formação moral que lhes desenvolvesse a virtude necessária para governar e governar-se.

\title{
3. As práticas de si como meio de construção subjetiva na antiguidade tardia \\ O cuidado de si, o hábito de refletir sobre aprópria conduta
} como meio de constituição de subjetividade e autodeterminação moral foi um fenômeno intelectual recorrente nos dois primeiros séculos de nossa era, de modo que as questões como uso e abuso dos prazeres, obrigações conjugais, relação com os pares e com os subordinados, sejam temáticas presentes tanto nos pensadores estoicos e epicuristas pagãos, quanto nos primeiros escritores cristãos, que se valiam destas considerações inclusive para denunciar a corrupção maligna dos costumes de sua época e reforçar a legitimidade da nova doutrina que traziam. Entre o posicionamento dos estoicos e dos epicuristas, uma das poucas distinções que podemos fazer em relação ao fato de que ambos praticavam a ascese através de exercícios de abstinência é destacar 
$|162|$

Epistemofilia, uso dos prazeres e cuidado de si:...

como, para estes últimos, a provação funcionava como um amplificador ao prazer das coisas simples, da satisfação das necessidades humanas mais básicas em oposição ao prazer fugaz das coisas supérfluas e do luxo, enquanto para os primeiros esta provação era fundamentalmente um treinamento para mais facilmente suportar eventuais privações, desenvolvendo o entendimento de que eram extremamente supérfluos e nocivos todos aqueles elementos oriundos do hábito, do gosto pela ostentação, como em um exercício de desapego mundano.

Outro fator contribuinte para este retraimento em forma de atenção para consigo pode ser evidenciado a partir de transformações sócio-políticas deste período, como o desprestígio e perda de poder político das classes aristocráticas e o enfraquecimento da estabilidade da cidades-estado enquanto unidades integradoras e constituintes de identidade pátria e pessoal. Diante da fatual derrocada do sistema político localizado representado por estas cidades e a concomitante perda de importância social dos membros da elite que, até então, tinham em seu papel de atores públicos quase que uma identidade própria, ocorreu um retraimento em direção a interioridade de si viabilizado pela reflexão filosófica que ainda era um sinal de prestígio social como o é, em geral, o acesso à cultura, estimulando o investimento na reflexão sobre sua própria vida, uma prática de si, e um privatização da existência.

A angústia em face de um universo demasiado vasto, que teria perdido suas comunidades políticas constituintes, poderia muito bem ser um sentimento que se atribui retrospectivamente aos homens do mundo greco-romano. [...] E se quisermos compreender o interesse, nessas elites, pela ética pessoal, pela moral do comportamento cotidiano, pela vida privada e pelos prazeres, não é tanto de decadência, de frustração e de retiro enfadonho que se deve falar; é preciso, ao contrário, ver aí a procura de uma nova maneira de refletir a relação que convém ter com o próprio status, com as próprias funções, as próprias atividades e obrigações (Foucault, 1988c, pp. 89 e 91). 


\begin{abstract}
Nesse sentido, percebe-se que, enquanto a ética antiga fazia uma conexão estreita entre o domínio de si como virtude e a possibilidade de, a partir de então, dominar os outros, neste período tardio a relação é fundamentalmente de si para consigo. Mas não apenas enquanto uma reflexão moral sobre si mesmo, e sim como uma ocupação prática e cotidiana consigo, uma epimeleia heautou. Enquanto aquela ocupação agonística consigo compunha uma exterioridade da ação moral, uma interpessoalidade, ainda que valorada pelo autodomínio, esta última faz com que a constituição de si mesmo como sujeito ético seja mais problematizada, pois esta dedicação a si requer mais do reflexão teórica, requer igualmente atividades práticas organizadas \}e elaboradas em forma de uma rotina.

Existem os cuidados com o corpo, os regimes de saúde, os exercícios físicos sem excesso, a satisfação, tão medida quanto possível, das necessidades. Existem as meditações, as leituras, as anotações que se toma sobre livros ou conversações ouvidas, e que mais tarde serão relidas, a rememoração das verdades que já se sabe, mas de que convém apropriar-se ainda melhor (Foucault, 1988c, p. 56).
\end{abstract}

Temos, portanto, dois níveis de ação na relação consigo mesmo: o teórico-reflexivo e o prático-comportamental. No primeiro deles, se está em face de si mesmo apenas, de si e de suas próprias memórias, comparando estes elementos com as teorias morais que se apreendeu a partir dos livros, das cartas, dos ensinamentos e dos diálogos com os sábios no sentido de orientar a própria conduta posterior da maneira mais racional e elevada moralmente possível. Nesse sentido, para a elaboração desta reflexão, se faz extremamente necessário um conhecimento de si, ponto no qual novamente o argumento do primeiro volume, de que saber é também de certa forma um meio de poder e controle, pode ser intuído. Não apenas tal procedimento está em conformidade com a gnose seautou socrática como também propicia toda uma reinterpretação da 
|164|

Epistemofilia, uso dos prazeres e cuidado de si:...

própria figura de Sócrates como um precursor dos ensinamentos da techne tou biou, da arte da existência.

$\mathrm{Na}$ verdade, toda uma arte do conhecimento de si foi desenvolvida, com receitas precisas, com formas específicas de exame e exercícios codificados. E na Apologia é enquanto mestre do cuidado de si que Sócrates se apresenta a seus juízes: o deus mandatou-o para lembrar aos homens que eles devem cuidar, não de suas riquezas, nem de sua honra, mas deles mesmos e de suas próprias almas. Ora, esse é o tema do cuidado de si, consagrado por Sócrates, que a filosofia ulterior retomou, e que ela acabou no cerne dessa "arte da existência" que ela pretende ser. [...] A fim de formular aquilo que é, ao mesmo tempo, princípio geral e esquema de atitude, Epíteto se refere a Sócrates assim como ao aforismo que está anunciado na Apologia: "Uma vida sem exame (anexatastos bios) não merece ser vivida" (Foucault, 1988c, pp. 50 e 68).

Porém, simultaneamente a esta atividade intelectual e filosófica, ocorre a cristalização de rotinas e comportamentos fundamentados nesta reflexão ética que compõe o aspecto de preocupação com o corpo dentro da moralidade da antiguidade tardia. Nesse momento, a medicina, através das dietas e dos regramentos, dos banhos, da prática sexual regular e da atividade física moderada, se configura em espaço privilegiado de cuidado de si enquanto corpo, evidenciando já uma possibilidade de se pensar, neste contexto, uma forma de biogovernamentalidade. Porém, tal cuidado com o corpo é muito diferente daquela preocupação aristocrático-guerreira que se tem como conceito primordial de virtude na sociedade clássica e arcaica antes dela, e sim um regramento do corpo com ares de sutileza, de disciplina, considerando o corpo não enquanto um fim em si mesmo ou elemento fundamental e privilegiado de espaço de vivência humana, e sim como invólucro temporário para a alma, esta sim a "essência" que deve ser cultivada. O cuidado com o corpo se dá, nesse caso, como manutenção de algo indigno a fim de torná-lo 
digno de, pelo menos, ser o portador material da consciência imaterial, da alma ou do espírito, sendo esta última a dimensão primordial para a qual se orienta a existência.

De qualquer forma, a moralidade sexual segue sendo o espaço privilegiado de problematização do comportamento social, o campo de força e conflito da constituição ética da subjetividade. Porém, diferentemente de ser uma caracterização da fortaleza moral entendida como domínio de si que se dá principalmente na medida da aceitação do desejo como algo natural e que, a despeito dessa espontaneidade deve ser reprimido ou exercido em conformidade com os critérios de necessidade, ocasião e posição social, esta relação tardia se dá numa ênfase à fragilidade do sujeito em fuga de seu desejo esmagador, de uma renúncia ao invés de um controle e, nesse sentido, prepara o estofo ético-psicológico para a moralidade cristã posterior.

\section{Conclusão}

Diversas considerações éticas podem surgir a partir da reelaboração dos elementos principais de A História da Sexualidade, principalmente se pensarmos este campo da sexualidade como um dos palcos mais fecundos de reflexão moral numa época de crescentes e constantes transformações nas sensibilidades individuais e de grupo como a que estamos vivendo. Um dos primeiros aspectos que poderíamos destacar é a que a problematicidade moral clássica considera a constante relação conflituosa entre o desejo e a sua possibilidade de satisfação, na medida em que é um exercício particular e individual, salvando espaço para a pluralidade, pois engloba em sua reflexão a possibilidade da diferença tanto em relação a si quanto em relação ao outro. Nesse sentido, percebe-se a emergência lenta de uma moralidade com tentáculos mais abrangentes como um esforço de padronização universalizável da consciência, seja através da imposição do argumento racional, seja através da dogmatização da governamentalidade pastoral, criando uma normatização homogeneizadora, intolerante e excludente como só a estreiteza 
$|166|$

Epistemofilia, uso dos prazeres e cuidado de si:...

de pensamento e a obtusidade intelectual, que, aliás, vingam férteis no campo adubado de nossa sociedade preconceituosa, sabem ser. Uma recuperação da moralidade clássica, ainda que seja um objetivo talvez utópico, poderia funcionar como o paradigma ético de um mundo plural.

Porém, ainda em relação à sexualidade, percebe-se que a eliminação das amarras e dos véus que envolvem o tema dificilmente serão retirados. Mesmo argumentando que vivemos uma época de mais liberdade e, na visão de alguns, permissividade excessiva, o que um olhar mais atento pode perceber é que a regulamentação da esfera sexual não se dá em forma de um banimento e sim, como coloca Foucault, de uma normatização e, no nosso contexto mais específico, de uma obrigatoriedade. O corpo, e a experiência existencial através desse corpo no campo da sexualidade, seguem sendo o espaço ideal da biogovernamentalidade na medida mesma em que a erotização, em forma de promessa de coito, seja um dos motores de nossa sociedade consumista em sua relação com os meios de comunicação e publicidade, o que tem reflexos imediatos nas mais diversas áreas da vivência humana.

O fato de que a problematicidade da moral sexual grega não se desenvolvesse em função do destino do desejo e sim da relação dos binômios aristotélicos de atividade/passividade, masculino/feminino, liberdade/submissão, nos insinua que a condenação nossa contemporânea do comportamento homossexual não é referente ao uso do corpo, e sim uma revolta em relação ao fato de que, em uma sociedade patriarcal, abrir mão de sua posição de dominador e ativo é uma ameaça ao poder opressor masculino como um todo. Isso talvez, além das possíveis e particularmente oportunas elaborações psicanalíticas sobre um homoerotismo recalcado, possa ajudar a explicar o fenômeno tão contundente da homofobia em suas manifestações mais violentas. A violência homofóbica intolerante pode ser lida como os últimos estertores de desespero do enfim derrotado macho solar dominador e, junto com ele, de uma civilização baseada no modelo patriarcal e na racionalidade instrumental. 


\section{Bibliografia}

ARISTÓTELES. Ética a Nicômaco. 3a ed. São Paulo: EDIPRO, 2009.

BAUMAN, Z. "Sobre a redistribuição pós-moderna do sexo: A História da Sexualidade, de Foucault, revisitada. In: BAUMAN, Z. O mal-estar da pós-modernidade. Rio de Janeiro: Jorge Zahar, 1998.

FOUCAULT, M. História da Sexualidade, v. I: A Vontade de Saber. Tradução: Maria Thereza da Costa Albuquerque e J. A. Guilhon Albuquerque. 12a ed. Rio de Janeiro: Edições Graal, 1988a.

História da Sexualidade, v. II: O Uso dos Prazeres. Tradução: Maria Thereza da Costa Albuquerque e J. A. Guilhon Albuquerque. 12a ed. Rio de Janeiro: Edições Graal. 1988b.

História da Sexualidade, v. III: O Cuidado de Si. Tradução: Maria Thereza da Costa Albuquerque e J. A. Guilhon Albuquerque. $12^{a}$ ed. Rio de Janeiro: Edições Graal, 1988c.

Vigiar e Punir. Petrópolis: Vozes, 1984.

GIACÓIA JÚNIOR, O. “Filosofia como diagnóstico do presente: Foucault, Nietzsche e a Genealogia da Ética". In: MARIGUIELA, Márcio (org.). Foucault e a destruição das evidências. Piracicaba: Editora Unimep, 1995.

MACHADO, R. Ciência e Saber: A trajetória da Arqueologia de Michel Foucault. Rio de Janeiro: Edições Graal, 1981.

RAJCHMANN, J. Foucault: A Liberdade da Filosofia. Rio de Janeiro: Jorge Zahar Editor, 1987. 